\title{
Gray Wolf Prey Base Ecology IN THE NORTH FORK OF THE FLATHEAD RIVER DRAINAGE
}

\section{Les Marcum $\downarrow$ DANIEL H. Pletscher $\bullet$ Michael BUREAU SCHOOL OF FORESTREY $\bullet$ UNIVERSITY OF MONTANA MISSOULA}

JOHN P. WEIGAND

MONTANA DEPARTMENT FISH, WILDLIFE, AND PARKS

During this reporting period, major goals of this project were to monitor elk (Cervus elaphus) in the North Fork of the Flathead River Drainage for mortality, monitor seasonal distribution and determine key areas of use, establish a repeatable index of elk abundance, and determine age/sex composition.

Two radio collared elk have died during the last six months. Both elk were killed in May by mountain lions (Felis concolor). This brings the mortality totals to seven elk killed by lions, two by wolves (Canis lupus), one by grizzly bear (Ursus arctos horribilis), and one by a hunter ( $\mathrm{n}=34$ radiocollared elk). Lions killed elk throughout the age distribution. Wolves took a calf and an old elk. The hunter killed a prime-aged elk, while the grizzly killed a 16-year-old elk.

Since 1 May, 528 aerial and ground locations have been obtained, bringing the total number of elk locations to over 1,100 . Elk were usually located twice a week during calving to determine important calving areas. There appeared to be no pattern with migration and calving. Some elk moved to summer range and then calved, while others interrupted migration to calve, then continued on to summer range. Only one elk, a non-migratory elk, calved on a winter range area. Migration distances ranged from zero to $60+\mathrm{km}$, and the animals more often proceeded from a south to north direction during spring than from east to west or west to east. Of 22 collared elk wintering in Montana, seventeen migrated to summer range in British Columbia. Of the five that stayed in Montana, one was nonmigratory, staying near the mouth of Coal Creek. The other four migrated north to the Whale Creek and Trail Creek drainages, the northernmost major drainages in Montana's Whitefish Range. None of the collared elk summered in Glacier National Park.

Elk appear to make heavy use of the many mineral licks found in the upper North Fork from mid-to-late summer. Use declined about the time of the first frosts, as did their use of high subalpine mountain basins. Elk movements increased greatly in September, probably because of mating activities and hunting pressure. The general hunting season in British Columbia and the bowhunting season in Montana began in early September.

Two of three methods to establish an index to the elk population were employed this spring. Elk pellet count data from the previous spring were analyzed to determine the number of plots needed for 
104

this year's pellet transects. Twelve hundred pellet plots were counted to detect a $20 \%$ change in the population. This year's data have not been analyzed. In addition, 191 elk were counted during five evening roadside surveys between 26 April and 2 May. Elk were counted along a specified route so that counts may be repeated annually. This number may be used in conjunction with the pellet index to monitor elk abundance.

Spring roadside counts were also used to determine cow/calf ratio before this year's new calves arrived. The ratio was 100:48, though it may be a high estimate due to a large number of unknowns (81). Only one antlered bull was seen. Thus, it is expected that winter aerial surveys are more accurate for determining age and sex composition.

Calving success and survivorship, which are secondary objectives of the study, were measured by aerially sighting collared elk during calving (15 May through 15 July) and afterwards by aerially counting large groups of elk $(n=546)$ to determine a cow/calf ratio. Sixty percent of the adult collared cows were seen with calves during calving. This number dropped to $40 \%$ by 15 August. Similarly, the cow/calf ratio determined from large groups of elk dropped from 100:50 in mid-June to 100:30 in midAugust. Calf survivorship and/or production appears to be down from last year when the January cow/calf ratio was 100:44. This may be due to a severe early winter and long-lasting snowpack, or simply to differences in sightability between summer and winter. Aerial surveys in January 1992 will determine whether difference in sightability was a factor. Elk will be located once a week and checked for mortality as often as possible for the remainder of the reporting period. 